\title{
Access to services: advocacy for abortion
}

\section{Lindsay Edouard}

Advisory Editor, Port Louis, Mauritius

\section{Correspondence to} Professor Lindsay Edouard: soranae@gmail.com

Received 9 July 2014 Accepted 22 July 2014
CrossMark

To cite: Edouard L. J Fam Plann Reprod Health Care 2014;40:297-299.

\section{SUMMARY}

Twenty-five years ago, in 1989, family planning services in Britain faced a serious crisis with contentious cuts for community clinics being contemplated by health authorities. There was extensive discussion on ethical issues relating to the provision of abortion services. Social acceptance of abortion occurred in association with departure from traditional values due to the exigencies of modern life. Twenty-five years later, in 2014, abortion unfortunately continues to cause controversy in international health, despite guidance for its incorporation in comprehensive reproductive health care services.

\section{SOURCE OF SERVICES}

By 1989, there should have been freedom from unwanted pregnancy in Britain through government recognition of the right of individuals to contraceptive services. But although those services were recognised as being highly effective, with a five-fold return on investment, they were unfortunately under threat. ${ }^{1}$ Family planning sessions in community clinics were suffering from the limited budgets of district health authorities, which used short-term vision and easy options to implement simple solutions for controlling costs. ${ }^{2}$ Cutbacks in service provision consisted either of the closure of clinics or a decrease in the number of sessions and of their staffing, while demand was reduced through inconvenient opening hours, poor premises and lack of prominent publicity to promote services.

Admittedly, the contraceptive services provided by general practitioners (GPs) were not adversely affected because of their separate funding through the openended budgets of Family Practitioner Committees. Nevertheless, this approach was regrettable as it failed to acknowledge the essential role of client choice in selecting the type of service delivery point, the value of anonymity and the convenience of on-site availability of supplies in community clinics. With the complementary nature of community clinics and GPs, a unified funding policy would have facilitated the provision of services during this crucial period for the family planning movement. As the poor state of community services had also led to job insecurity, difficulty in recruitment was feared, especially in view of the poor career structure: it was suggested that the solution would be to create a new cadre of community gynaecologists, "well-woman doctors", 1 who would reflect a symbiosis between contraception and gynaecology. ${ }^{3}$

\section{RECOURSE TO ABORTION}

David Bromham looked back to the horrific and atrocious days when pregnancy terminations were "in the hands of the criminal abortionists", and deprived and disadvantaged women were at increased risk due to the significant role of poverty in their decision to seek an abortion. Attempts by the anti-choice lobby to repeal the 1967 Abortion Act were supposedly aimed at the protection of 'innocent' intrauterine life. Unfortunately, this was a false argument and "driving termination into the backstreets once again would not save many fetal lives". 4

The continuing rise in induced abortions, "a source of disquiet and almost shame", was only partly explained by statements such as "women on welfare" are not good contraceptors" or that they were "using abortion as a method of contraception". The actual problem consisted mainly of inadequate contraceptive services, especially for teenagers, and changes in society such as deferring motherhood, and abortion serving as a "rite de passage" in regard either to selfimage or to dependency status. It was therefore felt that induced abortion "will have to be accepted as one of the unpleasant facts of complex present-day living, the lesser of two evils". 


\section{CONSPIRACY OF SILENCE}

Despite being widely available, official statistics on abortion had been largely underused, mainly due to fear of their misinterpretation. This situation was most unfortunate, especially in the quest for objective information that would facilitate policymaking: a prime example consisted of the discussions to reduce the upper time limit for inducing abortion in the context of technological advances. The National Association of Family Planning Doctors (NAFPD) provided active support for the proposal in Parliament to decrease the legal limit of fetal viability from 28 to 24 weeks. The association also supported embryo research and opposed unjustified cuts in clinic services, as reported at its annual general meeting. ${ }^{6}$

In a compelling lecture, Malcolm Potts reminded the audience that verbal prudery also contributes substantially to the intentional avoidance of any mention of abortion, and other matters sexual, in conversation. Ironically, we fail to realise or acknowledge that sex unconsciously pervades our lives, to the extent of being in the etymology of words such as testify, swivel, retired and hymn.

\section{ISSUES OF LIFE AND DEATH}

Having already debated life after death, the general public was increasingly interested in life before birth, especially in relation to ethical perspectives on induced abortion, human embryo research and the mode of action of contraceptive methods. Moreover, discussions on an abortion bill and a White Paper on embryo research in the British Parliament increased interest in matters relating to early pregnancy.

It was apt that NAFPD provided crucial support for a publication of presentations from the First International Conference on Philosophical Ethics in Reproductive Medicine, which had provided a forum for valuable discussions, bearing in mind that "moral decisions must be based on reasoned argument and not simply on 'gut reaction' or emotional outbursts". ${ }^{8}$ An analysis of Vatican Instruction, "beyond the mere value of religious authority", for a definition of the start of a new human life, emphasised respect for dignity of the person whilst commenting that "what appears as 'prohibition' today can turn into 'prophecy' tomorrow". ' The perspective of Aristotle on conception, that the male seeds from semen grew in the menstrual blood of the uterine field, had prevailed until the 17 th century. With the limited optical definition of early compound microscopes, biologists thought that they observed, within every sperm, the presence of a homunculus, a little man, which theologians claimed had the role of ensoulment at coitus. ${ }^{7}$

Based on pagan ethics, the Hippocratic Oath includes a pledge to cause no harm, thereby forswearing abortion, fully in line with Judeo-Christian doctrine. However, this traditional approach must be adapted to modern medical practice where there is greater emphasis on relief of suffering as opposed to healing, the reproductive rights of the woman within the mother-fetus dyad, and respect, which is subjective as compared to the former absolute principle of sanctity of human life. ${ }^{10}$ Criteria for personhood are more complex than mere brainstem life because, for example, protection is not provided to sentient creatures such as cattle. ${ }^{8}$ Regarding the potential to become persons, a prime case relates to the status of sperm and unfertilised eggs in relation to contraception, including deliberate sexual abstinence. Moral respect for the products of human reproduction is set out in social criteria and legal frameworks such as the arbitrary cut-off point for fetal viability that is used as the upper time limit for inducing abortion. Finally, positions on the morality of abortion are sometimes the opposite to real-life actions: those against liberal abortion policies might themselves seek abortion when having to face certain unforeseen personal situations. ${ }^{11}$

Malcolm Potts demonstrated the value of a biosocial framework to analyse the reproductive agendas in various cultures so as to understand beliefs and behaviour, especially persisting myths that arise from rational explanations. He concluded by stating that whereas sex and sin had led to expulsion from paradise for eating the fruit of the tree of knowledge, we should now use scientific knowledge to guide our reproductive behaviour, to "open the gates of a paradise on earth". 7

\section{CURRENT IMPLICATIONS}

And now, 25 years on, there continue to be major changes in sexual and reproductive health services in England. With their commissioning being transferred from the National Health Service to local government, improved co-ordination is needed for general practice and specialty services, including genitourinary medicine. While worldwide there are now only five countries where abortion is illegal under any circumstances, the challenge is to improve access to services, as illegal abortion is universally recognised as being a prime cause of preventable maternal mortality.

There are numerous international initiatives for collaboration between countries to share experiences to improve abortion care. ${ }^{12}$ The World Health Organization has produced excellent guidance for the provision of abortion services ${ }^{13}$ but ideally this should be complemented by national guidelines on specific issues, as exemplified by the clarification of roles and responsibilities by the UK Department of Health on 23 May $2014 .{ }^{14}$

However, recent developments in techniques for early medical abortion are not yet adequately addressed in current abortion legislation and associated guidance. In Bangladesh, for example, abortion is illegal, except to save the life of a woman, but 'menstrual regulation' is widely accessible through a legal arrangement whereby this intervention can be done in the absence of confirmation of pregnancy. ${ }^{12}$ As 
induced abortions can be carried out with the same equipment that is used for the evacuation of retained products of conception following incomplete miscarriage, the clinical provision of services is facilitated. The international challenge therefore consists of policy formulation and resulting implementation to improve access, as opposed to mere legislation to give legal status to abortion. The outcome of the current discussions at the United Nations on the post-2015 follow-up to the Millennium Development Goals ${ }^{15}$ will be crucial for the future of abortion services, depending on the priority that will be accorded to sexual and reproductive health during the next two decades as a component of the Sustainable Development Goals.

\section{Competing interests None.}

Provenance and peer review Not commissioned; internally peer reviewed.

\section{REFERENCES}

1 Mills A. Family planning - through the looking glass. Br J Fam Plann 1989;15(Suppl. 1):49-52.

2 Cox ML. Clinic closures - trust betrayed. Br J Fam Plann 1989;15:1-2.

3 Bromham DR. Contraception and gynaecology. Br J Fam Plann 1989;15:69-70.

4 Bromham DR. What would recriminalising abortion achieve? Br J Fam Plann 1989;14:109.

5 Christopher E. Abortion in the 1980s. Br J Fam Plann 1989;15:21-22.

6 Anonymous. Minutes of AGM. Br J Fam Plann 1989;15:103-104.
7 Potts M. The 15th Jennifer Hallam Memorial Lecture - with sex in mind. Br J Fam Plann 1989;15(Suppl. 1):3-10.

8 Brown J. Towards a defence of experimentation on human embryos. In: Bromham D, Forsythe E, Dalton M (eds), Ethical Problems in Reproductive Medicine. London, UK: National Association of Family Planning Doctors, 1989:16-20.

9 Spagnolo AG, Di Petro ML, Sgreccia E. Reproductive technologies in light of the Vatican Instruction. In: Bromham D, Forsythe E, Dalton M (eds), Ethical Problems in Reproductive Medicine. London, UK: National Association of Family Planning Doctors, 1989:21-24.

10 Sims PF, de S Cameron NM. New medicine for old - the demise of the Hippocratic tradition. In: Bromham D, Forsythe E, Dalton M (eds), Ethical Problems in Reproductive Medicine. London, UK: National Association of Family Planning Doctors, 1989:34-35.

11 Hayry M. Selecting our offspring - some objections and counterobjections. In: Bromham D, Forsythe E, Dalton M (eds), Ethical Problems in Reproductive Medicine. London, UK: National Association of Family Planning Doctors, 1989: 36-38.

12 Zaidi S, Begum F, Tank J, et al. Achievements of the FIGO initiative for the prevention of unsafe abortion and its consequences in south-southeast Asia. Int J Gynaecol Obstet 2014;126(Suppl. 1):S20-S23.

13 Department of Reproductive Health and Research. Clinical Practice Handbook for Safe Abortion. Geneva, Switzerland: World Health Organization, 2014.

14 Sexual Health Policy Team. Guidance in Relation to Requirements of the Abortion Act 1967. London, UK: Department of Health, 2014.

15 Horton R. WHO offers a new future for sustainable development. Lancet 2014;383:1872. 